\title{
Chemical Composition of the Lipophylic Extract from the Tunicate Botryllus schlosseri
}

\author{
Krasimir Slantchev ${ }^{\mathrm{a}}$, Kamen Stefanov ${ }^{\mathrm{a}}$, Katya Seizova ${ }^{\mathrm{a}}$, Simeon Popov ${ }^{\mathrm{a},{ }^{*}}$ and \\ Stoitse Andreev ${ }^{\mathrm{b}}$ \\ a Institute of Organic Chemistry with Centre of Phytochemistry, Bulgarian Academy of \\ Sciences, Sofia 1113, Bulgaria. Fax: (003592) 700-225. E-mail: simpopov@orgchm.bas.bg \\ (S. Popov) \\ b Museum of Natural History, Bulgarian Academy of Sciences, Sofia 1000, Bulgaria \\ * Author for correspondence and reprint requests \\ Z. Naturforsch. 55c, 794-798 (2000); received March 14/May 11, 2000 \\ Botryllus schlosseri, Phospholipids, Sterols
}

Eighteen sterols were identified in Botryllus schlosseri, stanols being the main sterols. The sterol composition is in agreement with our recent paper on taxonomic separation of tunicates into three groups. Again we found in invertebrates of the Black Sea sterols with a (22Z)-double bond. This confirms the presence of such sterols in nature. The composition of the phospholipids appeared to be complex, and twelve groups of them were identified in Botryllus schlosseri. The main representatives of phospholipids appeared to be phosphatidylcholine and phosphatidylethanolamine. Only four volatile compounds were identified, which is unusual for marine invertebrates.

\section{Introduction}

Animals from the Botryllidae family, phylum Chordata, subphylum Urochordata (Tunicata), class Ascidiacea, suborder Stolidobronchiata show a colonial form of life. Individuals are placed in groups. Each group has one common cloakal opening. The form and the size of a colony depends on its maturity and may rich $10 \mathrm{~cm}$ in width and $3 \mathrm{~cm}$ in height. A great amount of pigments causes color variability from lemon yellow to dark brown. The only representative of this family in the Black Sea is Botryllus schlosseri. This species is almost a cosmopolitan and inhabits the sea bottom in depths of 1-65 m. There are only few investigations on the sterols and phospholipids from tunicates. It was found that the main sterol component in the members of Ascidiacea is cholesterol, its amount may reach $65 \%$ of total sterols in some species (Tam Ha et al., 1982), in addition to different $\Delta^{5}$ sterols and stanols. In some cases stanols appeared to be the main sterol group (Ballantine et al., 1977; Shubina et al., 1981). Zollo et al., (1986) investigated sterols from four ascidians and found that they contain coprostanols ( $5 \beta$-stanols) in addition to regular 4-demethylsterols. $4 \alpha-$ Methyl sterols and coprostanols were found in $A s$ cidia nigra (Tam Ha et al., 1982) and four other tunicates from the Mediterranean Sea (Voogt and Van Rheenen, 1975). The identification of $5 \alpha, 8 \alpha-$ epidioxy sterols in some tunicates (Gunatilaka et al. , 1981) is an indication for the presence of ergosterol type compounds. Preliminary research on sterols from B. schlosseri (Popov et al., 1984) with high temperature GC/MS showed a presence of small amounts of $\Delta^{5,7}$ sterols in this invertebrate, the main ones being 7-dehydro analogs of cholesterol and 24-methylcholesta-5,22-dien-3 $\beta$-ol.

The polyunsaturated fatty acids, 6,9,12-octadecatrienoic acid, 5,8,11,14,17-eicosapentaenoic acid and 4,7,10,13,16-docosahexaenoic acid were found together, with other fatty acids, in B. schlosseri and associated bacteria (Carballeira et al., 1995). Kostetsky and Naumenko(1984) identified as main

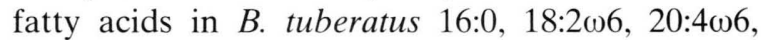
$20: 5 \omega 3$ and $22: 6 \omega 3$ and as main phospholipids phosphatidylcholine and phosphatidylethanolamine.

\section{Materials and Methods}

\section{Investigation of the sterol fraction}

GC: Pye Unicam 304, equipped with a FID and a capillary column SPB-1 $(30 \mathrm{~m} \times 0.32 \mathrm{~mm}$, $0.25 \mu \mathrm{m})$. Temperature program $230{ }^{\circ} \mathrm{C}-300^{\circ} \mathrm{C}$ 
at $4{ }^{\circ} \mathrm{C} \cdot \mathrm{min}^{-1}$ and a $10 \mathrm{~min}$ hold. Injector temperature $-300^{\circ} \mathrm{C}$, detector temperature $-320^{\circ} \mathrm{C}$. Carrier gas $-\mathrm{N}_{2}$, linear velocity $-35 \mathrm{~cm} . \mathrm{sec}^{-1}$.

GC/MS: Hewlett Packard 6890 + MS5973 with a capillary column SPB-50 $(30 \mathrm{~m} . \times 0.32 \mathrm{~mm}$, $0.25 \mu \mathrm{m}$. He was used as carrier gas, linear velocity was $40 \mathrm{~cm} \cdot \mathrm{sec}^{-1}$ with a temperature program $270{ }^{\circ} \mathrm{C}-290{ }^{\circ} \mathrm{C}$ at $4{ }^{\circ} \mathrm{C} \cdot \mathrm{min}^{-1}$ and a $20 \mathrm{~min}$ hold.

NMR: Bruker $250 \mathrm{MHz}$, in $\mathrm{CDCl}_{3}$.

\section{Investigation of volatiles}

GC/MS: Hewlett Packard 6890 + MS5973 with a capillary column HP-5MS $(30 \mathrm{~m} . \times 0.32 \mathrm{~mm}$, $0.25 \mu \mathrm{m})$. He was used as a carrier gas, linear velocity was $32 \mathrm{~cm} . \mathrm{sec}^{-1}$ with a temperature program $40^{\circ} \mathrm{C}-280^{\circ} \mathrm{C}$ at $6^{\circ} \mathrm{C} \cdot \mathrm{min}^{-1}$ and a $10 \mathrm{~min}$ hold.

\section{Collection of Botryllus schlosseri}

The tunicate was collected in September 1999 at Maslen nos area in the southern part of the Bulgarian Black Sea coast at a depth of 7 meters. Animals were immediately dipped in ethanol.

\section{Isolation and analysis of sterols}

$150 \mathrm{~g}$ of the collected animals were homogenized with a hand mixer in ethanol. The material obtained was filtered and three times extracted with chloroform-ethanol $(1: 1 \mathrm{v} / \mathrm{v})$. Total extracts were combined and the $\mathrm{CHCl}_{3}$ layer collected. The chloroform solution was evaporated to dryness and $200 \mathrm{mg}$ of the crude mixture were subjected to column chromatography on $20 \mathrm{~g}$ of silica gel. As eluents were used petroleum ether, followed by petroleum ether : acetone mixtures (100:3, 100:5, 100:8 v/v), chloroform and chloroform-methanol mixtures (100:2, 100:5 10:1, 10:3, $2: 1,1: 4.0: 1 \mathrm{v} / \mathrm{v}$ ) in ascending polarity. Samples of $20 \mathrm{ml}$ were collected. Fractions containing sterols were identified by TLC on silica gel plates and combined. The total sterol mixture was investigated by GC, GC/MS and ${ }^{1} \mathrm{H}-\mathrm{NMR}$.

\section{Isolation and analysis of volatile substances}

Part of the dry $\mathrm{CHCl}_{3}$ extract $(100 \mathrm{mg}$ ) was subjected to steam distillation for five hours using a Liken-Nickerson apparatus (Hendriks et al., 1981). The collected distillates were extracted with di- ethyl ether, the extracts dried over $\mathrm{Na}_{2} \mathrm{SO}_{4}$ and evaporated under reduced pressure at $30^{\circ} \mathrm{C}$. The obtained volatiles $(0.010 \mathrm{~g})$ were investigated by GC/MS.

\section{Analysis of polar lipids}

The content of plasmalogen, alkylacyl and diacylglycero phospholipids was determined according to Dembitsky (1988). The method is based on mild basic deacylation and acidic hydrolysis of plasmalogens on silica gel plates and two - dimensional thin layer chromatography. Plates were developed in the first direction with chloroform methanol - 28\% ammonia solution (130:70:10, v/ $\mathrm{v})$, and in the second direction with chloroform acetone - methanol - acetic acid - water (100:40:20:20:10, v/v).

\section{Results and Discussion}

\section{Sterol composition}

The sterol composition of Botryllus sp. has not yet been investigated except for one investigation on $\Delta^{5,7}$ - sterols (Popov et al., 1984). Total sterol fraction was isolated by column chromatography of the lipophylic extract, followed by preparative TLC.

GC and GC/MS analysis allowed the identification of 18 sterols in Botryllus schlosseri from the Black Sea. The results obtained are summarized in Table I. In this table are shown the most characteristic mass spectral data for the identified sterols. The main sterols were cholesterol and $5 \alpha$-cholestanol, as in the most of the investigated tunicates (Elyakov and Stonik, 1988; Goad, 1978). In significant concentrations we also found 24-methylcholesta-5,22-dien-3 $\beta$-ol, which is produced mainly by the phytoplankton. Its appearance together with 24-methylcholesta-5,24(28)-3ß-ol, which is also a phytoplankton sterol, is an indication that the diet of B. schlosseri in Black Sea contains significant amounts of phytoplankton. Both sterols discussed above are accompanied by their dihydro analogs with a saturated C-5 double bond (Table I). Small amounts of $\Delta^{7}$ and $\Delta^{5,7}$-sterols were also found, and these are characteristic for most of the tunicates investigated (Goad, 1978). The sterol composition obtained is similar to other tunicates, belonging to the suborder Stolidobronchiata. This 
Table I. Sterol composition of Botryllus schlosseri.

\begin{tabular}{|c|c|}
\hline Sterol & $\%$ from the total sterols \\
\hline 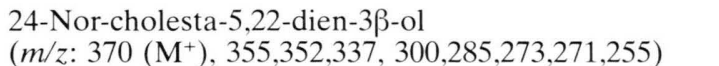 & 0.5 \\
\hline 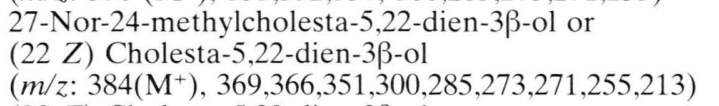 & 1.5 \\
\hline $\begin{array}{l}(22 E) \text { Cholesta-5,22-dien-3ß-ol } \\
\left(m / z: 384\left(\mathrm{M}^{+}\right), 369,366,351,300,285,273,271,255,213\right)\end{array}$ & 2.5 \\
\hline $\begin{array}{l}\text { Cholesterol } \\
\left(\mathrm{m} / z: 386\left(\mathrm{M}^{+}\right), 371,368,353,301,275,273,255,231,213\right)\end{array}$ & 9.0 \\
\hline $\begin{array}{l}5 \alpha-\text { Cholestanol } \\
\left(\mathrm{m} / z: 388\left(\mathrm{M}^{+}\right), 373,370,355,262,257,234,233,216,215\right)\end{array}$ & 17.0 \\
\hline 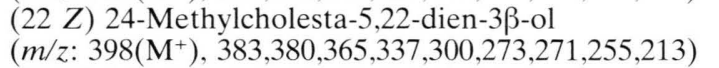 & 7.0 \\
\hline $\begin{array}{l}(22 \mathrm{Z}) \text {-24-Methylcholest-22-en-3ß-ol } \\
\left(\mathrm{m} / \mathrm{z}: 400\left(\mathrm{M}^{+}\right), 385,382,367,302,284,273,233,215\right)\end{array}$ & 10.0 \\
\hline 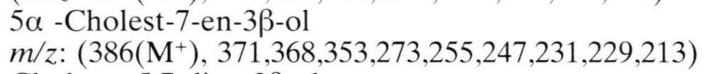 & 0.2 \\
\hline $\begin{array}{l}\text { Cholesta-5,7-dien-3 } \beta \text {-ol } \\
\left(\mathrm{m} / \mathrm{z}: 384\left(\mathbf{M}^{+}\right), 369,366,351,325,271,253,211\right)\end{array}$ & 2.4 \\
\hline 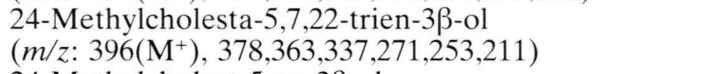 & 2.7 \\
\hline $\begin{array}{l}\text { 24-Methylcholest-5-en-3 } \beta \text {-ol } \\
\left(\mathrm{m} / z: 400\left(\mathbf{M}^{+}\right), 385,382,367,273,315,289,273,271\right)\end{array}$ & 2.0 \\
\hline 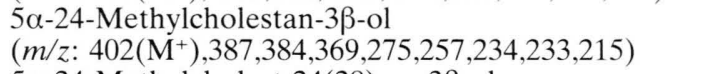 & 3.0 \\
\hline 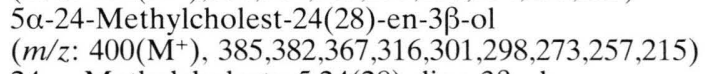 & 17.0 \\
\hline 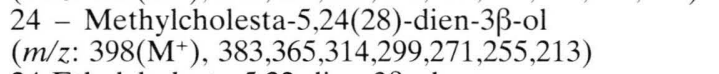 & 7.0 \\
\hline $\begin{array}{l}\text { 24-Ethylcholesta-5,22-dien-3ß-ol } \\
\left(\mathrm{m} / \mathrm{z}: 412\left(\mathrm{M}^{+}\right), 397,394,379,351,300,273,271,255,213\right)\end{array}$ & 3.0 \\
\hline $\begin{array}{l}24 \text { - Ethylcholest-22-en-3ß-ol } \\
\left(\mathrm{m} / \mathrm{z}: 414\left(\mathrm{M}^{+}\right), 399,396,381,302,275,273,257,233\right)\end{array}$ & 6.0 \\
\hline $\begin{array}{l}24 \text {-Ethylcholest-5-en-3ß-ol } \\
\left(\mathrm{m} / \mathrm{z}: 414\left(\mathrm{M}^{+}\right), 399,396,381,329,315,303,273,255,213\right)\end{array}$ & 2.0 \\
\hline 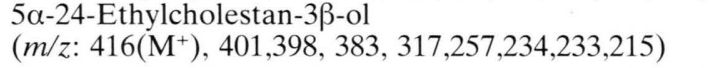 & 1.0 \\
\hline
\end{tabular}

is in agreement with the recently proposed by us taxonomic separation of the same suborder into three groups according to their sterol composition (Slantchev et al., 2000). The first group includes Microcosmus sp. and Halocynthia sp. In the second group are included some representatives from the Ascidiidae, Cionidae and Molgulidae families. The third group includes representatives of Styelidae family. Botryllus schlosseri is biologically close to the representatives of the second group of tunicates. Its sterol composition, especially the presence of high concentrations of stanols and the detection of ergosterol type compounds is in agreement with the proposed taxonomic scheme.
The methods used (GC and GC/MS) are applied in almost all investigations on sterol mixtures but in complex sterol mixtures from marine organisms some problems arise which could not be solved only by GC/MS investigations. The first one is the identification of the stanols in the mixtures. While $5 \beta$-stanols have different RT values on the GC column, the most common $5 \alpha$-stanols have practically identical RRT with the corresponding $\Delta^{5}$ - sterols (RRT $=1.01$ for $5 \alpha$-cholestanol compared with $\mathrm{RRT}=1$ for cholesterol) and can not be separated well even on a capillary column. Our mass spectra showed a presence of stanols, mixed with the corresponding $\Delta^{5}-$ sterols. For this reason we investigated total sterol mixtures by ${ }^{1} \mathrm{H}$ NMR and the 
ratio of the areas of the peaks for $\mathrm{H}-3(\delta 3.57)$ and for H-5 ( $\delta 5.36)$ gave the concentration of the $5 \alpha-$ stanols in the sterol mixture. The ${ }^{1} \mathrm{H}-\mathrm{NMR}$ spectrum of the total sterol mixture showed also that it contained only desmethyl sterols and no 4methyl sterols $(\mathrm{H}-3$ for the last ones appeared at $\delta 3.0)$.

The main sterols in the investigated organism according to the ${ }^{1} \mathrm{H}$-NMR spectrum were $5 \alpha$-stanols (about $70 \%$ from the total sterol mixture), followed by $\Delta^{5}$ - sterols. The last ones are the typical dietary sterols in the sea and are found in different concentrations in all marine invertebrates. In some cases, especially in sponges, the dietary sterols are transformed in the invertebrate organisms in order to satisfy some specific membrane requirements (Djerassi and Silva, 1991; Elenkov et al., 1997). Transformations of $\Delta^{5}-$ sterols into stanols were proved in many organisms. In significant part of the investigated tunicates (Elyakov and Stonik, 1988; Shubina et al., 1981) stanols were identified as important sterol constituents, which is an indication that in these animals transformation of dietary sterols into stanols could take place. This was in agreement with our results.

The ${ }^{1} \mathrm{H}-\mathrm{NMR}$ spectrum of the total sterol mixture gives an important information about the stereochemistry of the C-22 double bond. The multiplet at $\delta 5.17$ with coupling constant $10.5 \mathrm{~Hz}$ is characteristic for a cis-double bond. The presence of (22Z)-double bond was proposed in the short-necked clam Tapes philippinarum (Goad, 1978), but later many authors rejected the presence of such double bond. Only recently such sterols were found in a terrestrial plant (Akihisa et al., 1990) and in a Black Sea hydrozoan, Obelia longissima (De Rosa et al., 1999 ). The NMR data and the GC comparison with an authentic sample from $O$. longissima unambiguously showed that more than $90 \%$ from the 24-methylcholesta-5,22dien -3 $\beta$-ol and 24-methylcholest-22-en-3 $\beta$-ol in $B$. schlosseri contained a cis-double bond at C-22. The protons at the C-22 trans-double bond produced signals separated from these for the cisdouble bond protons and this allowed the measurement of the ratio of the both isomers. In $O$. longissima the main sterol was identified as the (22Z)-isomer of 24-methylcholesta-5,22-dien-3 $\beta$-ol (De Rosa et al., 1999). The same sterol was identified now as one of the main sterols in B. schlos- seri. 27-Nor-24-methylcholesta-5,22-dien-3 $\beta$-ol and (22Z)-cholesta-5,22-dien-3 $\beta$-ol have identical GC retention times and mass spectral fragmentation, so they could not be distinguished in this work.

\section{Phospholipid composition}

There is data on the phospholipid composition of only two members of the Botryllidae family (Kostetsky and Naumenko, 1984). It was found that phosphatidylcholine (PC) and phosphatidylethanolamine $(\mathrm{PE})$ are the main representatives of phospholipids in these animals. Our data (see Table II) confirms this statement - PC $(30.5 \%)$ is the main phospholipid, followed by PE $(10.2 \%)$. The phospholipid mixture apparently had a complex composition - twelve different groups were identified. The lysophospholipids were in low concentrations. They can appear as a result of a partial hydrolysis of phospholipids. The concentration of the alkyl-acylphosphatidylcholine (AAPC) was high, similarly to other evolutionary higher marine invertebrates (Dembitsky, 1986). Plasmalogens were found in relatively low concentrations.

Table II. Composition of the total phospholipid mixture in Botryllus schlosseri.

\begin{tabular}{lc}
\hline PHOSPHOLIPID & $\begin{array}{c}\text { \% from total } \\
\text { phospholipids }\end{array}$ \\
\hline Lysophosphatidylcholine + & 3.0 \\
lysophosphatidylethanolamine & 2.2 \\
Phosphatidylinositol & 7.0 \\
Sphingomyeline & 30.5 \\
Phosphatidylcholine & 18.0 \\
Alkyl-acylphosphatidylcholine & 10.2 \\
Phosphatidylethanolamine & 3.0 \\
Plasmalogen & 2.2 \\
Phosphatidylserine & 3.5 \\
Phosphatidylglycerol & 2.6 \\
Diphosphatidylglycerol & 1.5 \\
Phosphatidic acid & 6.2 \\
Phytosphingomyelin & \\
\hline
\end{tabular}

\section{Volatile compounds}

Volatile substances are studied mainly in terrestrial plants (essential oils) and in some cases in algae (Koning and Wright, 1996). Recently we found that in algae and in marine invertebrates (sponges and bryozoans) the volatiles contain extremely complex mixtures of secondary metabolites (unpublished results). From their composition it can be concluded that they act as allelochemicals (defensive compounds, attractants, etc.). There are 
no investigations on volatile compounds from tunicates. We isolated volatiles from $B$. schlosseri by hydrodistillation. The composition of the volatiles was studied by GC/MS. 2,3-Butandiol appeared to be the main volatile component. Also we found small amounts of butyl hydroxytoluene and methyl esters of tetradecanoic and hexadecanoic acids. Fatty acid methyl esters have been isolated in many cases, but sometimes they appeared to be artifacts, because methanol, used for the extractions, can preesterify the lipids. We did not use methanol in the isolation procedure, so the methyl esters obtained are not artifacts. This is the first isolation of natural fatty acid methyl esters from

Akihisa T., Tamura T., Matsumoto T., Kokke W. C. M.C., Ghosh P. and Thakur S. (1990), $(22 Z, 24 S)$ - stigmasta - 5,22,25 - trien-3 $\beta$-ol and other novel sterols from Clerodendrum scandens: First report on the isolation of a cis- $\Delta^{22}$-unsaturated sterols from a higher plant. J. Chem. Soc. Perkin Trans I, 2213-2218.

Ballantine J. A., Lavis A. and Roberts J. C. (1977), Marine sterols XV. Sterols of some oceanic holothurians. J. Exp. Mar. Biol. Ecol. 30, 29-35.

Carballeira N. M., Shalabi F., Stefanov K., Dimitrov K., Popov S., Kujumgiev A. and Andreev St.(1995), Comparison of the fatty acids of the tunicate Botryllus schlosseri from the Black Sea with two associated bacterial strains. Lipids 30, 677-679.

Dembitsky V. M.(1986), Phospholipid and fatty acid composition of Echinodermates 1. Class Ophiuroidea. Khim. Prir. Soed. 547-551.

Dembitsky V. M. (1988), Quantification of plasmalogen, alkylacyl and diacyl glycerophospholipids by microthin-layer chromatography. J. Chromatogr. 436, 467473.

De Rosa S., Milone A., Popov S. and Andreev St.(1999). Sterol composition of the Black Sea Hydrozoan Obelia longissima (Pallas 1766), Comp. Biochem. Physiol. 123B, 229-233.

Djerassi C. and Silva C. J.(1991), Sponge Sterols: Origin and biosynthesis. Acc. Chem. Res. 24, 371-378.

Elenkov I., Dragova B., Andreev St. and Popov S.(1997), $4 \alpha$-Methyl sterols from the Sponges Haliclona cinerea and Haliclona flavenscens. Comp. Biochem. Physiol. 118B, $155-157$.

Elyakov G. B. and Stonik B. A. (1988), Sterols from marine invertebrates. In: Steroids from Marine Organisms, Kamernitskii, A. B. Moscow, Nauka, pp. $123-$ 125.

Goad L. J. (1978), The sterols of marine invertebrates: composition, biosynthesis, and metabolites. In: Marine Natural Products, Chemical and Biological Perspectives, Vol. 2 (Scheuer P. J., ed.). Academic Press, New York, San Francisco, London, pp. 75-172. volatiles of marine animals. The composition of the volatiles in B. schloseri appeared to be very simple, compared with this of other marine invertebrates (unpublished results). Such simple volatiles composition is characteristic for vertebrates, which is in agreement with the specific systematic place, between two phyla, occupied by tunicates. Further investigations on other tunicates are necessary to confirm this hypothesis.

\section{Acknowledgement}

The authors are grateful to the Bulgarian National Council for Scientific Research for the partial financial support of this work (Project X-710).

Gunatilaka A., Gopichand Y., Schmitz F. and Djerassi C. (1981), Minor and trace sterols in marine invertebrates. 26. Isolation and structure elucidation of nine new $5 \alpha, 8 \alpha$ - epidioxy sterols from four marine organisms. J. Org. Chem. 46, 3860-3866.

Hendriks H., Geerts J. and Malingre Th. (1981), The occurrence of valeranone and crypto -fauronol in the essential oil of Valeriana officinalis L. s. l. collected in the northern part of The Netherlands. Pharmaceutisch Weekblad, Scientific Edition 116, 1316-1320.

Koning G. M. and Wright A. D. (1996), Marine natural products research: current direction and future potential. Planta Med. 62, 193-211.

Kostetsky E. and Naumenko N. (1984), Comparative study of fatty acid composition of phospholipids in marine invertebrates. Khim. Prirod. Soed., 24-29. (Russ).

Popov S., Stoilov I. and Demirev P. (1984), Gas chromatographic/mass spectrometric method for the identification of $\Delta^{5,7}$-sterols in sterol mixtures. Biomed. Mass Spectrom. 11, 608-610.

Shubina L., Moskovkina T., Stonik V. and Elyakov G. (1981), Steroid alcohols from ascidia Halocynthia aurantium. Khim. Prir. Soed. 581-585. [Russ]

Shubina L., Stonik V. and Elyakov G. (1981), Steroid alcohols from Ascidia nigris. Khim. Prir. Soed. 104106. [Russ]

Slantchev K., Popov S. and Andreev S. (2000), Sterol composition of tunicates. Bulg. Chem. Ind., in press.

Tam Ha T., Kokke W. and Djerassi C.(1982), Minor sterols of marine invertebrates, 37. Isolation of novel coprostanols and $4 \alpha$-methyl sterols from the tunicate Ascidia nigra. Steroids 40, 433-454.

Voogt P. A. and Van Rheenen J. W. (1975), Sterols of some ascidians. Arch. Intern. Physiol. Biochem. 83, $563-572$.

Zollo F., Finamore E., Gargiulo D., Ricco R. and Minale L.(1986), Marine sterols. Coprostanols and $4 \alpha$-methyl sterols from Mediterranean tunicates. Comp. Biochem. Physiol. 85B, 559-560. 